Article

\title{
Anti-Tick Microbiota Vaccine Impacts Ixodes ricinus Performance during Feeding
}

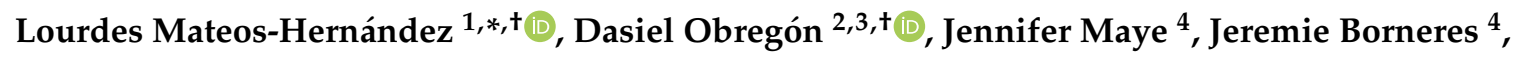 \\ Nicolas Versille ${ }^{4}$, José de la Fuente ${ }^{5,6}{ }^{\circledR}$, Agustín Estrada-Peña ${ }^{7}{ }^{\circ}$, Adnan Hodžić ${ }^{8}$, \\ Ladislav Šimo ${ }^{1}$ al and Alejandro Cabezas-Cruz ${ }^{1, * \mathbb{C}}$ \\ 1 UMR BIPAR, INRAE, ANSES, Ecole Nationale Vétérinaire d'Alfort, Université Paris-Est, Marie Curie, \\ 94706 Maisons-Alfort, France; ladislav.simo@vet-alfort.fr \\ 2 School of Environmental Sciences, University of Guelph, Guelph, ON N1G 2W1, Canada; \\ dasielogv@gmail.com \\ 3 Center for Nuclear Energy in Agriculture, University of São Paulo, Piracicaba 13400-970, Brazil \\ 4 SEPPIC Paris La Défense, 92250 La Garenne Colombes, France; jennifer.maye@airliquide.com (J.M.); \\ jeremie.borneres@airliquide.com (J.B.); Nicolas.VERSILLE@airliquide.com (N.V.) \\ 5 SaBio, Instituto de Investigación en Recursos Cinegéticos (IREC-CSIC-UCLM-JCCM), \\ 13005 Ciudad Real, Spain; jose_delafuente@yahoo.com \\ 6 Department of Veterinary Pathobiology, Center for Veterinary Health Sciences, Oklahoma State University, \\ Stillwater, OK 74078, USA \\ 7 Faculty of Veterinary Medicine, University of Zaragoza, 50009 Zaragoza, Spain; aestrada@unizar.es \\ 8 Institute of Parasitology, Department of Pathobiology, University of Veterinary Medicine Vienna, \\ Vienna 1210, Austria; Adnan.Hodzic@vetmeduni.ac.at \\ * Correspondence: lourdes.mateos@vet-alfort.fr (L.M.-H.); cabezasalejandrocruz@gmail.com (A.C.-C.) \\ + These authors contributed equally to this work.
}

Received: 26 October 2020; Accepted: 18 November 2020; Published: 21 November 2020

\begin{abstract}
The tick microbiota is a highly complex ensemble of interacting microorganisms. Keystone taxa, with a central role in the microbial networks, support the stability and fitness of the microbial communities. The keystoneness of taxa in the tick microbiota can be inferred from microbial co-occurrence networks. Microbes with high centrality indexes are highly connected with other taxa of the microbiota and are expected to provide important resources to the microbial community and/or the tick. We reasoned that disturbance of vector microbiota by removal of ubiquitous and abundant keystone bacteria may disrupt the tick-microbiota homeostasis causing harm to the tick host. These observations and reasoning prompted us to test the hypothesis that antibodies targeting keystone bacteria may harm the ticks during feeding on immunized hosts. To this aim, in silico analyses were conducted to identify keystone bacteria in the microbiota of Ixodes nymphs. The family Enterobacteriaceae was among the top keystone taxa identified in Ixodes microbiota. Immunization of $\alpha-1,3$-galactosyltransferase-deficient-C57BL/6 ( $\alpha 1,3 \mathrm{GT} \mathrm{KO})$ mice with a live vaccine containing the Enterobacteriaceae bacterium Escherichia coli strain BL21 revealed that the production of anti-E. coli and anti- $\alpha$-Gal IgM and IgG was associated with high mortality of $I$. ricinus nymphs during feeding. However, this effect was absent in two different strains of wild type mice, BALB/c and C57BL/6. This result concurred with a wide distribution of $\alpha$-1,3-galactosyltransferase genes, and possibly $\alpha$-Gal, in Enterobacteriaceae and other bacteria of tick microbiota. Interestingly, the weight of I. ricinus nymphs that fed on E. coli-immunized C57BL/6 was significantly higher than the weight of ticks that fed on C57BL/6 immunized with a mock vaccine. Our results suggest that anti-tick microbiota vaccines are a promising tool for the experimental manipulation of vector microbiota, and potentially the control of ticks and tick-borne pathogens.
\end{abstract}

Keywords: anti-tick microbiota vaccines; tick control; $\alpha$-Gal 


\section{Introduction}

Non-pathogenic microbes associated with ticks impact vector physiology and survival [1]. Some endosymbionts, such as Francisella sp., contribute to the synthesis of vitamin B, a nutritional component essential for ticks and absent in the blood meal. The nutritional complementation by Francisella sp. is fundamental for tick development and survival [1]. Beyond endosymbiotic bacteria, other genera such as Pseudomonas, Sphingobacterium, Acinetobacter, Enterobacter, and Stenotrophomonas are common colonizers of the midgut in hard ticks [2]. Vitamin B synthesis genes are not restricted to Francisella [1] or Coxiella [3], but are widely distributed in some genera of tick microbiota [4]. This suggests that nutritional complementation in ticks can be an attribute not only of symbionts, but also of tick microbiota bacteria [4]. In addition, the diversity of genes and metabolic pathways encoded in the bacterial genomes of the tick microbiome suggests that the contribution of bacteria to tick physiology and survival could go beyond vitamin B supplementation [4,5]. A functional complementation between tick and gut microbiota genomes is expected, considering the strong phylosymbiotic signal of microbial communities associated to Ixodid ticks [6]. However, the theoretical prediction of tick-microbiota phylosymbiosis has not been empirically tested [6]. To fill this gap, it is necessary to develop tools to assess the role of specific microbiota bacteria in tick development, physiology and survival. Microbial communities harbor keystone taxa which are highly connected and have a great explanatory power of the community structure and functioning irrespective of their abundance [7]. Keystone taxa drive community composition and function and can be identified using co-occurrence networks [7-9]. Due to their central role in the microbial networks, removal or addition of keystone taxa may be associated with major shifts in the whole community structure.

The synthesis of the glycan Gal $\alpha 1-3 \mathrm{Gal} \beta 1-4 \mathrm{GlcNAc}-\mathrm{R}(\alpha-\mathrm{Gal})$ by the enzyme $\alpha$-1,3-galactosyltransferase occurs in bacteria [10-13], fungi [14-16], and noncatarrhine mammals [17], but prokaryotic and eukaryotic $\alpha$-1,3-galactosyltransferase genes and proteins share little structural homology [18-20]. Humans, old world monkeys and apes evolved with the inability to synthesize $\alpha$-Gal, which resulted in the capacity to produce anti- $\alpha-\mathrm{Gal} \operatorname{IgM} / \operatorname{IgG}$ antibodies with a protective activity against pathogenic viruses (e.g., HIV), bacteria (e.g., Mycobacterium) and parasites (e.g., Plasmodium), containing this modification on membrane proteins [21-23]. The natural IgM/IgG antibodies against $\alpha-G a l$ are produced in response to gut microbiota bacteria having this modification [21,24]. Several bacteria of the family Enterobacteriaceae such as Klebsiella pneumonia [10], Escherichia coli [11,12] and Salmonella spp. [13,24] are known to express $\alpha 1,3$-galactosyltransferase genes, and to synthetize $\alpha$-Gal, in the human gut microbiome [24]. Similar to humans, nonmammalian vertebrates such as fish, amphibians, reptiles and birds do not express the $\alpha$-Gal epitope $[17,25,26]$, which makes them able to produce anti- $\alpha$-Gal antibodies in response to gut colonization with bacteria expressing $\alpha-G a l$. Tick saliva contains glycoproteins with $\alpha$-Gal modifications that can induce in some individuals the production of high levels of anti- $\alpha-G a l$ IgE associated with allergic reactions [27-30]. It has been proposed that the presence of $\alpha-\mathrm{Gal}$ in ticks may be a mechanism of molecular mimicry of the vector to escape the immunity of the vertebrate host producing endogenous $\alpha$-Gal and incapable of producing high levels of natural anti- $\alpha$-Gal antibodies $[19,31]$. Currently, three hypotheses explain that the origin of $\alpha$-Gal in ticks could be due to: (i) residual mammalian glycoproteins or glycolipids from a previous blood meal of a nonprimate mammal, (ii) endogenous $\alpha-G a l$ synthesis by ticks, and (iii) pathogenic or non-pathogenic bacteria (symbionts or microbiota) present in the ticks and able to produce $\alpha$-Gal. Evidence supporting hypotheses (i) and (ii) have been published [29], while the hypothesis in (iii) remains to be tested.

In this work, we used network analysis to identify keystone taxa in tick gut microbiota. A live bacteria vaccine was then used to target Enterobacteriaceae bacteria, one of the identified keystone taxon. Using a functional metagenomic approach, we predicted the presence of $\alpha 1,3$-galactosyltransferase genes in Enterobacteriaceae and other bacteria of the tick gut microbiome. Our results showed for the first time that immunization with defined members of tick gut microbiota can be used to modulate tick physiology and microbiota composition. In addition, the results suggest that tick microbiota may be a 
source of $\alpha$-Gal with unknown relevance for tick-induced allergy and that anti- $\alpha$-Gal immunity may play a protective role against tick infestation. We conclude that host immunization with selected vector microbiota bacteria is a promising tool for the experimental manipulation of vector gut microbiota, and potentially vector and vector-borne pathogen control.

\section{Results}

\subsection{Enterobacteriaceae Is a Keystone Bacterial Family in Ixodes Gut Microbiota}

In the first step of this work, we used a multifactor approach for the screening of potential keystone taxa in the gut microbiota of Ixodes ticks, based on: (i) eigencentrality, (ii) ubiquitousness, and (iii) the combination of relative abundance and eigencentrality. Two previously published datasets [32,33], from 16S rRNA (16S) sequences of Ixodes gut microbiota were used to identify keystone taxa. One dataset from Ixodes scapularis nymphs reared in laboratory conditions [32], and the other from free-living Ixodes ricinus nymphs collected in the Swiss Alps at different altitudes [33]. Bacteria co-occurrence networks were used to quantify and rank the centrality of bacterial families present in the gut microbiota of I. scapularis and I. ricinus nymphs. The selection of bacteria was based on eigencentrality, which is a measure of the influence of a node in a network [34]. Several bacterial families resulted central in the co-occurrence networks from both I. scapularis and I. ricinus microbiota (Figure 1a). The ubiquitousness of the taxa was addressed by identifying the microbial families present across all the samples of I. scapularis and I. ricinus nymphs. The analysis revealed greater taxon richness in the I. scapularis microbiota compared with $I$. ricinus. Thirty families were identified as the core microbiota of I. scapularis, while in I. ricinus only five families were present in all the samples (Figure 1b). Only four families were found in all samples from both datasets: Enterobacteriaceae, Corynebacteriaceae, Pseudomonadaceae and Sphingomonadaceae.

a)

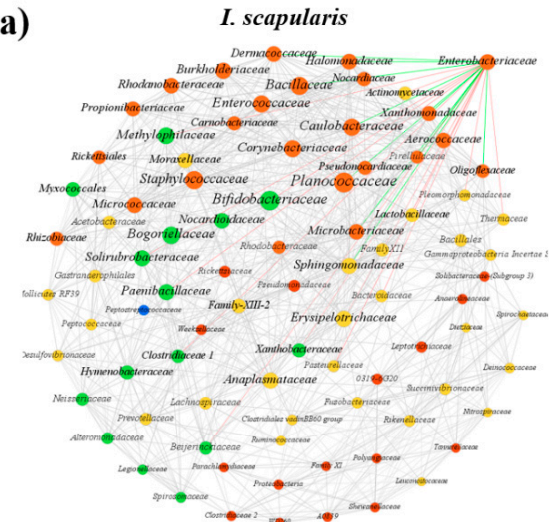

b)

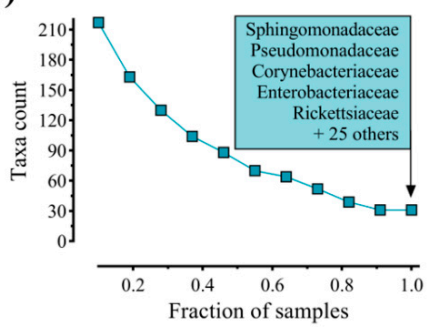

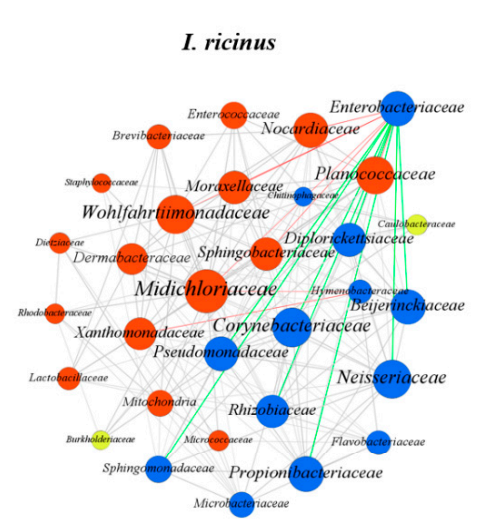

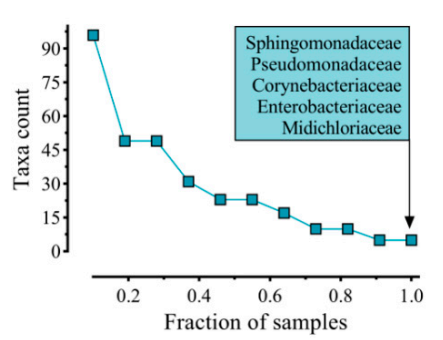

Figure 1. Interactions and ubiquitous bacterial families on the gut microbiota of I. scapularis 
and I. ricinus nymphs. (a) Co-occurrence bacterial networks obtained from $16 \mathrm{~S}$ sequences. Nodes correspond to taxa (family level), and connecting edges indicate significant $(p<0.01)$ and strong positive or negative correlations (SparCC $>0.7$ or $<-0.7$ ). Only nodes with at least one significant correlation are represented. Node colors are based on modularity class metric, hence the same color mean modules of co-occurring taxa. The size of the nodes is proportional to the eigencentrality of each taxon. Enterobacteriaceae is highlighted (top right), and the connecting edges differentiated in positive (green) and negatives (red). (b) Identification of the ubiquitous families across the samples in each data set. Four families were found in all samples $(n=20)$ from both I. scapularis and I. ricinus nymphs.

As a third screening criterion, we used the combination of relative abundance and eigencentrality. The list of bacterial families identified in I. scapularis and I. ricinus, including relative abundance and eigencentrality values, is available as Supplementary Table S1. In both I. scapularis (Figure 2a) and $I$. ricinus (Figure $2 b$ ), Enterobacteriaceae was among the bacterial families with the highest relative abundance and eigencentrality. Among the four ubiquitous families in both Ixodes species (Figure 1b), Enterobacteriaceae and Corynebacteriaceae had the highest values of eigencentrality and relative abundance (Table 1). Based on the ubiquitousness, high eigencentrality, and the combination of high relative abundance and eigencentrality in both Ixodes species, Enterobacteriaceae and Corynebacteriaceae were selected as keystone taxa. However, in this study, only Enterobacteriaceae was used in downstream experiments, as a proof of concept. Within the family Enterobacteriaceae, bacteria of the genus Escherichia-Shigella were the second most represented taxa in I. scapularis (Figure 2c) and the only taxa represented in I. ricinus (Figure $2 \mathrm{~d}$ ).

Table 1. Eigencentrality and relative abundance values of ubiquitous bacterial families in Ixodes spp. ticks.

\begin{tabular}{lcccc}
\hline \multirow{2}{*}{$\begin{array}{c}\text { Ubiquitous } \\
\text { Bacterial Families }\end{array}$} & \multicolumn{2}{c}{ Eigencentrality * } & \multicolumn{2}{c}{ Relative Abundance * } \\
\cline { 2 - 5 } & I. scapularis & I. ricinus & I. scapularis & I. ricinus \\
\hline Enterobacteriaceae & 0.69 & 0.69 & 17.83 & 5.36 \\
\hline Corynebacteriaceae & 0.79 & 0.85 & 5.76 & 2.04 \\
\hline Pseudomonadaceae & 0.42 & 0.67 & 5.66 & 19.42 \\
\hline Sphingomonadaceae & 0.71 & 0.40 & 0.96 & 9.61 \\
\hline \multicolumn{5}{c}{ *Values as in Supplementary Table S1. }
\end{tabular}



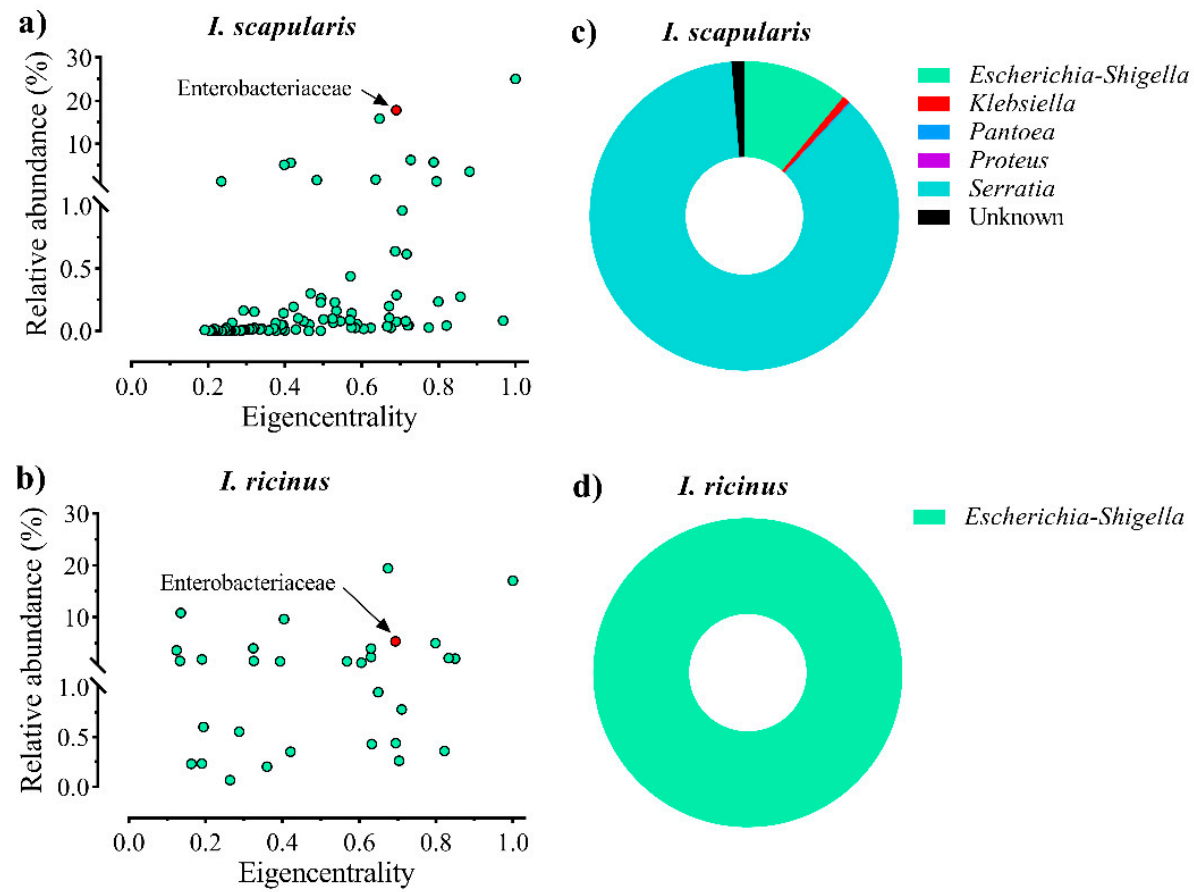

Figure 2. Eigencentrality and relative abundance of bacterial families in I. scapularis and I. ricinus microbiota. Relative abundance of all bacterial families was plotted as a function of their eigencentrality in the co-occurrence networks of (a) I. scapularis and (b) I. ricinus microbiota. Only families with at least one significant correlation with other nodes in the networks are displayed. Circles represent bacterial families and Enterobacteriaceae was highlighted (red color). The taxonomic composition (\%) of Enterobacteriaceae according to bacterial genera are represented in donut chart for both (c) I. scapularis and (d) I. ricinus microbiota.

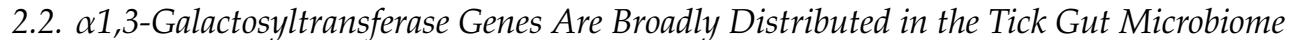

Bacteria of the family Enterobacteriaceae are known to express $\alpha 1,3$-galactosyltransferase genes and to synthetize the $\alpha$-Gal glycan in the human gut microbiome [10-13,24,35]. However, the presence and distribution of these genes in the tick microbiome remain unknown. Here, we used the functional metagenomic inference approach PICRUSt2 [36] to assess the distribution of $\alpha 1,3$-galactosyltransferase bacterial genes in Ixodes gut microbiota. Several $\alpha 1,3$-galactosyltransferase genes including $g s p A$-general secretion pathway protein A (K02450), waaL, rfaL-O-antigen ligase [EC:2.4.1.-] (K02847), waaO, rfaI-UDP-glucose: (glucosyl) LPS alpha-1,3-glucosyltransferase [EC:2.4.1.-] (K03275), waaj, rfaJ; UDP-glucose: (galactosyl) LPS alpha-1,2-glucosyltransferase [EC:2.4.1.58] (K03279) and waaR, waaT, rfaJ- UDP-glucose/galactose:(glucosyl)LPS alpha-1,2-glucosyl/galactosyltransferase [EC:2.4.1.-] (K03276) were identified in the microbiome of I. scapularis and I. ricinus. The gene waal, rfaI-UDP-D-galactose: (glucosyl) LPS alpha-1,3-D-galactosyltransferase [EC:2.4.1.44] (K03278) was identified only in I. scapularis (Figure 3). The PICRUSt2 pipeline also allowed tracing the contribution of each $16 \mathrm{~S}$ amplicon sequence variant (ASV) to the predicted genes. In I. scapularis, the $\alpha$-1,3-galactosyltransferase genes were traced to 22 classified bacterial families, one ASV from the phylum Gammaproteobacteria, unclassified at the family level, and other unassigned ASV (Figure 3a). Among these genes, the $\mathrm{KO} 2847$ and $\mathrm{KO} 2450$ were the most abundant on the functional microbiome of I. scapularis, and the largest contribution came from Enterobacteriaceae bacteria metagenomes, followed by Burkholderiaceae, and the set of unassigned ASVs. In the I. ricinus microbiome, the five genes were traced to 11 classified bacterial families and, as in I. scapularis, the genes $\mathrm{KO} 2847$ and $\mathrm{KO} 2450$ were the most abundant on the functional microbiome of I. ricinus (Figure 3b). 

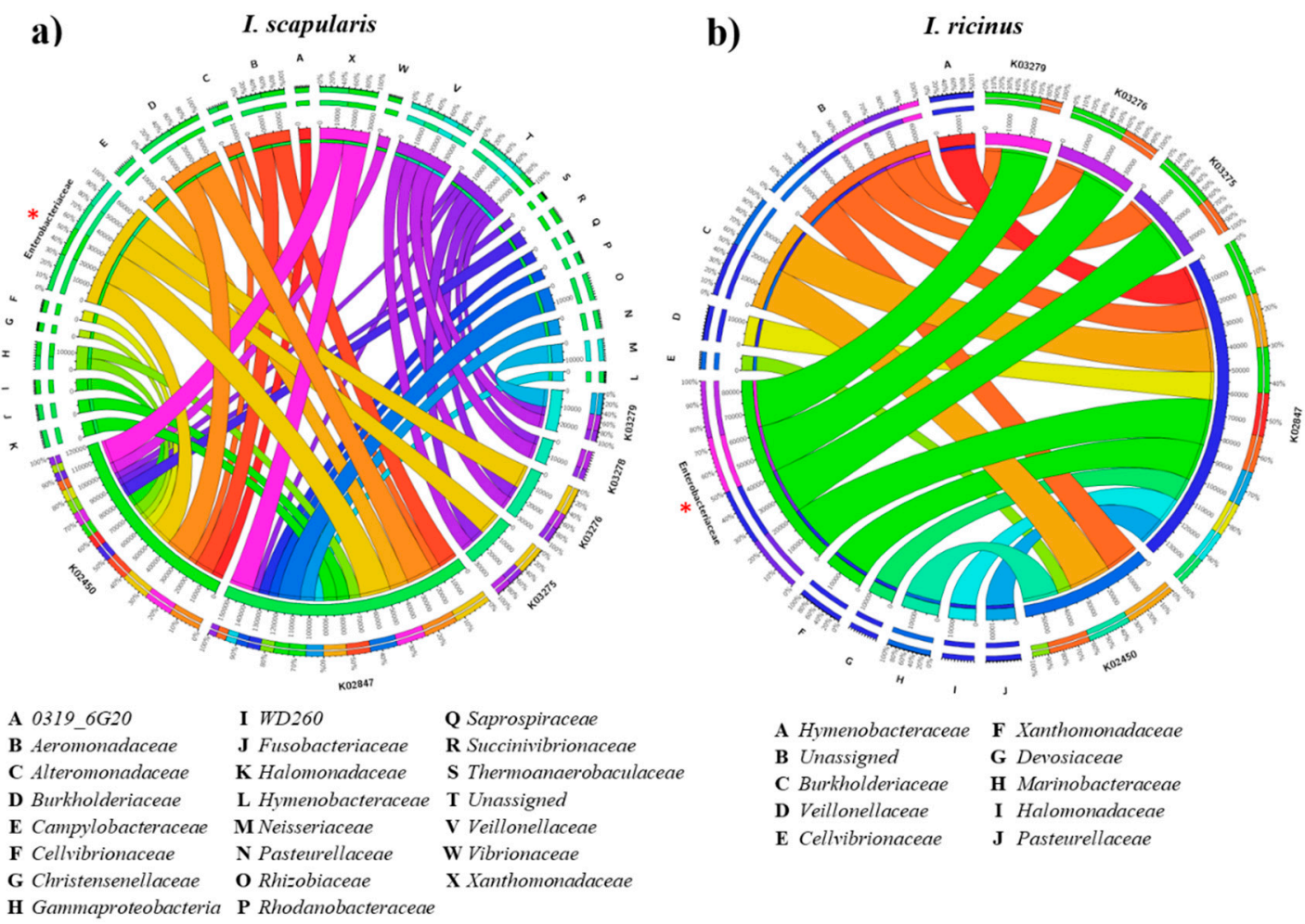

Figure 3. Metagenome contribution to $\alpha 1$,3-galactosyltransferase genes in the gut microbiota of (a) I. scapularis, and (b) I. ricinus nymphs. The position of Enterobacteriaceae was highlighted (red *). KEGG orthology and taxonomic contribution was predicted using PICRUSt2. Chord diagrams show the linkage between classified and unclassified (unassigned) taxa and $\alpha 1,3$-galactosyltransferase genes. The arcs indicate connections, represented proportionally by the size of each arc. Node segments along a circle represent taxa or functional genes, the node size indicates the abundance (measured as feature count) of contributing taxa and genes. Chord diagrams were made with the visualization tool "Circos" [37].

To validate the results generated by PICRUSt2, we tested midguts of 25 laboratory-reared I. ricinus female ticks for the presence of the selected bacterial $\alpha 1,3$-galactosyltransferase genes. Overall, two out of five pools tested (midguts of five ticks per pool) showed positive results in PCRs and sequence analyses revealed $100 \%$ identity to the corresponding genes expressed by different E. coli and Shigella sp. strains. PCR amplification of waaR gene revealed a band of the expected size ( $685 \mathrm{bp})$, but we failed to sequence the amplicon. The representative nucleotide sequences of the bacterial $\alpha 1,3$-galactosyltransferase genes were deposited in the GenBank database and are available under the following accession numbers: MW222477 (gspA-general secretion pathway protein A), MW222479 (waaL, rfaL-O-antigen ligase), MW222480 (waaO, rfaI-UDP-glucose:(glucosyl)LPS alpha-1,3-glucosyltransferase), and MW222478 (waaJ, rfaJ-UDP-glucose:(galactosyl)LPS alpha-1,2-glucosyltransferase).

\subsection{Anti- $\alpha$-Gal Immunity and Host Genetic Background Influence the Impact of Live E. coli Vaccination on Tick Performance}

The initial hypothesis of this study was that targeting keystone bacteria within the tick microbiota with host antibodies could impact tick performance. The discovery of Enterobacteriaceae as a keystone taxon in Ixodes microbiota, and the high distribution of $\alpha 1,3$-galactosyltransferase genes in Enterobacteriaceae and other tick microbiota bacteria, prompted us to test the impact of anti- $\alpha-\mathrm{Gal}$ immunity on tick performance after immunization with Enterobacteriaceae bacteria. To this aim, we used the $\alpha$-1,3-galactosyltransferase-deficient-C57BL/6 ( $\alpha 1,3 \mathrm{GT} \mathrm{KO})$ mice, the only available nonprimate mammals that can produce natural anti- $\alpha-\mathrm{Gal} \operatorname{IgM}$ and $\operatorname{IgG}$ in titers similar to those 
in humans. Wild type C57BL/6 mice having the same genetic background as $\alpha 1,3 \mathrm{GT}$ KO mice, but expressing a functional copy of the ggtal gene, were used as controls. Mice were immunized with a live vaccine containing the Enterobacteriaceae bacteria E. coli strain BL21. Sera samples were collected during the experiment (Figure 4a). Immunization with E. coli induced the production of IgM and IgG to E. coli proteins in both $\alpha 1,3 \mathrm{GT}$ KO and C57BL/6 mice (Figure $4 \mathrm{~b}$ ). The levels of anti- $\alpha-\mathrm{Gal}$ IgM increased after immunization in both mice strains when compared with the control animals of the same strain (Figure 4c). However, C57BL/6 mice failed to developed anti- $\alpha-\mathrm{Gal}$ IgG even sixteen days (d30) after the second immunization, while this antibody increased significantly in $\alpha 1,3 \mathrm{GT}$ KO mice after the first immunization (d14). A slight, but significant, increase in anti- $\alpha$-Gal IgG was recorded in C57BL/6 mice on d46 (Figure 4c).

a)
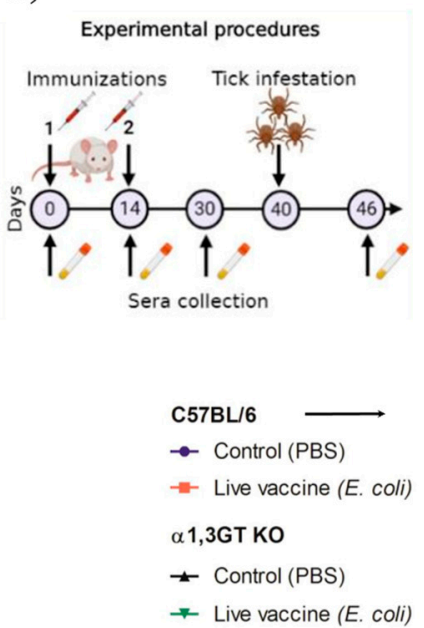

b)
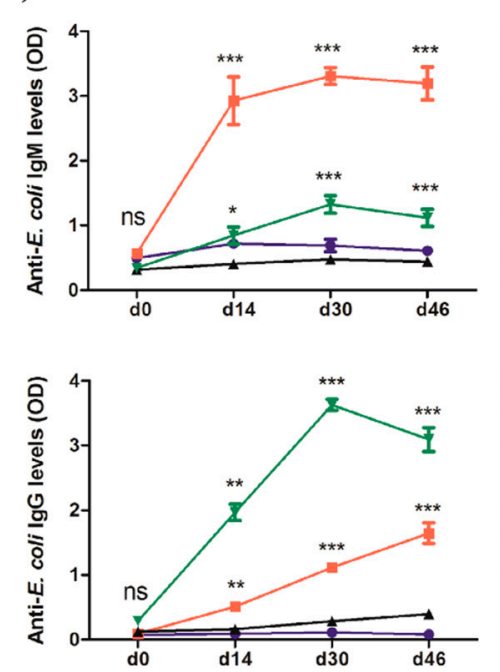

c)
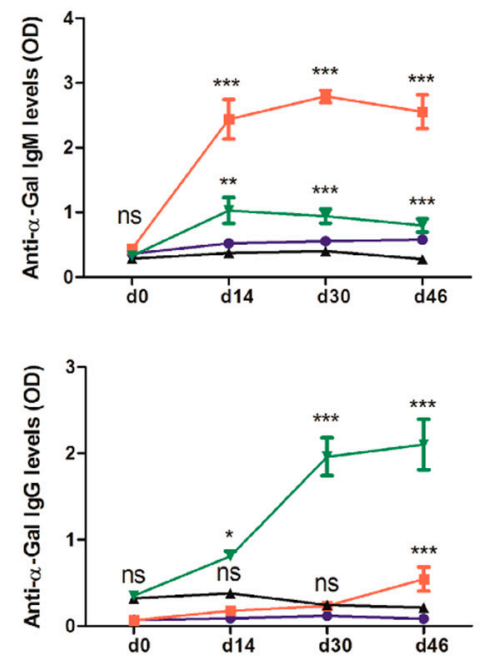

Figure 4. Antibody response of C57BL/6 and $\alpha 1,3 \mathrm{GT}$ KO mice after immunization with a live E. coli vaccine. (a) Mice were immunized twice and then infested with I. ricinus nymphs. The levels of IgM and IgG to E. coli proteins (b) and $\alpha$-Gal (c) were quantified in sera by ELISA. Results shown are means and standard error values. Results were compared by two-way ANOVA with Bonferroni test applied for comparisons between control and immunized mice within each strain C57BL/6 or $\alpha 1,3 \mathrm{GT}$ KO $\left({ }^{*} p<0.05,{ }^{* *} p<0.001,{ }^{* * *} p<0.0001\right.$, ns-not significant; 1 experiment for each mice strain, $n=10$ $\alpha 1,3 \mathrm{GT}$ KO mice, $n=10 \mathrm{C} 57 \mathrm{BL} / 6$ mice and three technical replicates per sample).

Mice developed a white vaccine deposit located at the injection point due to the nature of the adjuvant. However, no mortality was associated with E. coli immunization and no sign of pain was observed after the vaccination. We hypothesized that the water-in-oil emulsion of the vaccine protected the mice from a sudden discharge of the bacteria, avoiding sepsis and a septic shock. Following the immunization protocol, each mouse was infested with 5 ( $\alpha 1,3 \mathrm{GT} \mathrm{KO}$ ) or 20 (C57BL/6) I. ricinus nymphs. Time to complete feeding, weight of engorged ticks and tick mortality were recorded and compared between immunized and control groups of the same mice strain (Figure 5). The ticks feeding on E. coli-immunized $\alpha 1,3 \mathrm{GT}$ KO mice started dropping at $\mathrm{d} 4$, one day after the ticks that were feeding on the E. coli-immunized C57BL/6 mice (Figure 5a). More than $70 \%$ of I. ricinus nymphs that fed on control $\alpha 1,3 \mathrm{GT}$ KO mice dropped on day 4 , while less than $40 \%$ of the ticks that fed on the E. coli-immunized mice dropped on day 4 (Figure 5a). There were no significant differences in the proportion of ticks that dropped from E. coli-immunized or control C57BL/6 mice on $\mathrm{d} 3, \mathrm{~d} 4$ or $\alpha 1,3 \mathrm{GT} \mathrm{KO}$ on $\mathrm{d} 5$ or in the total amount of ticks that dropped from each mouse regardless of the strain (Figure 5a). Immunization with E. coli did not affect the mortality of ticks that fed on C57BL/6 mice, but produced a significant increase in the mortality of ticks that fed on $\alpha 1,3 \mathrm{GT}$ KO (Figure $5 \mathrm{~b}$ ). The weight of ticks that dropped on $\mathrm{d} 4, \mathrm{~d} 5(\alpha 1,3 \mathrm{GT} \mathrm{KO})$ and $\mathrm{d} 4(\mathrm{C} 57 \mathrm{BL} / 6)$ was not affected by E. coli 
immunization (Figure 5c). However, the weight of ticks that dropped from E. coli-immunized C57BL/6 on $\mathrm{d} 3$ was significantly higher than the ticks that fed on the control group. The weight of all ticks from E. coli-immunized C57BL/6 was also significantly higher than the control (Figure 5c).

a)

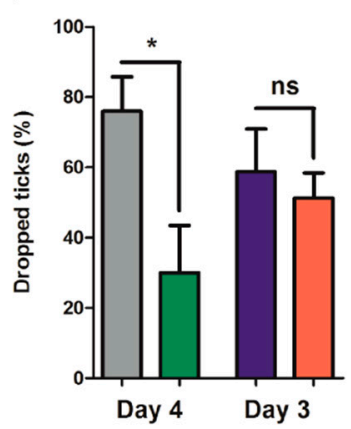

c)

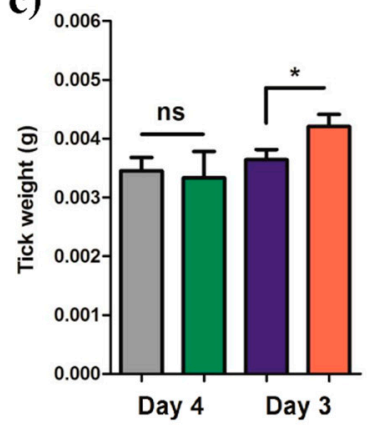

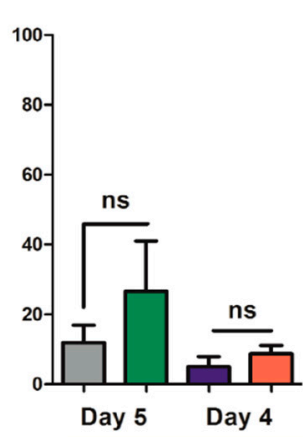

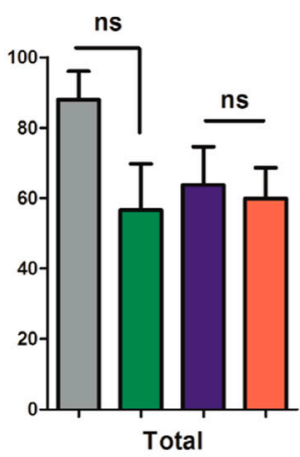

b)

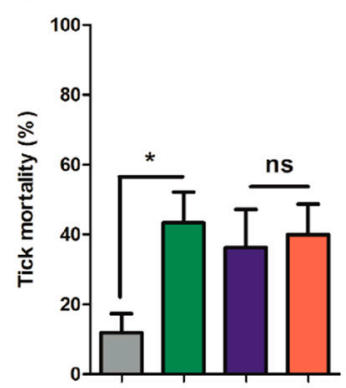

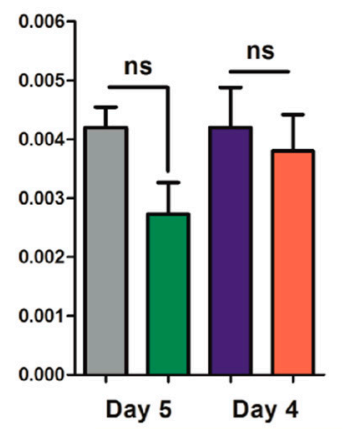

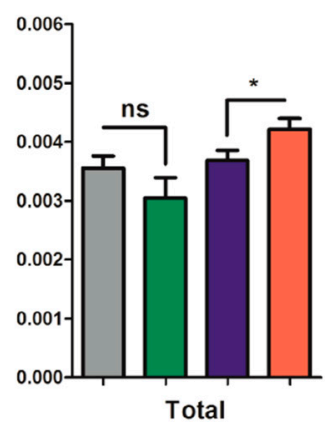

C57BL/6

$\square$ Control (PBS)

$\square$ Live vaccine (E. coli)

$\alpha 1,3 \mathrm{GT}$ KO

$\square$ Control (PBS)

$\square$ Live vaccine (E. coli)

Figure 5. Performance of I. ricinus nymphs feeding on $\alpha 1,3 \mathrm{GT}$ KO and C57BL/6 mice immunized with live E. coli. (a) The percentage of ticks that dropped on day 3, 4 or 5 , and the total, was calculated and compared between groups. (b) The percentage of dead ticks was calculated and tick mortality (\%) compared between groups. (c) At the end of feeding, the weight of individual ticks was measured and compared between groups. Means and standard deviation values are displayed. Results were compared within each mouse strain by Mann-Whitney U test. $\quad\left({ }^{*} p<0.05\right.$, ns-not significant; 1 experiment for each mouse strain, $n=12 \alpha 1$,3GT KO mice ( $n=5$ ticks per mouse), $n=10 \mathrm{C} 57 \mathrm{BL} / 6$ mice ( $n=20$ ticks per mouse)).

To further test the role of the anti-microbiota vaccine, another mouse strain, BALB/c, was immunized and infested with ticks following the experimental procedures presented in Figure 4 a. BALB/c mice express a functional copy of the ggta1 gene and are not capable of producing natural anti- $\alpha$-Gal antibodies, as C57BL/6. Immunization with E. coli induced the production of IgG to E. coli proteins (Figure 6a) and $\alpha$-Gal (Figure 6b) in BALB/c mice. However, these mice failed to produced anti-E. coli (Figure 6a) and anti- $\alpha$-Gal IgM in response to E. coli immunization (Figure 6b). None of the parameters measured on the ticks, i.e., time to complete feeding (Figure 6c), tick mortality (Figure 6d) and weight of engorged ticks (Figure 6e), was significantly affected after E. coli vaccination in BALB/c mice. 


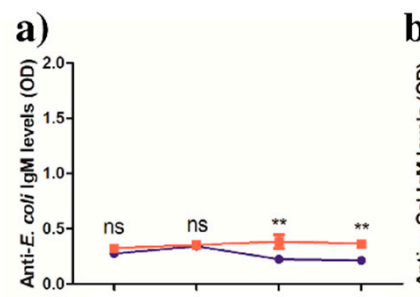

b)

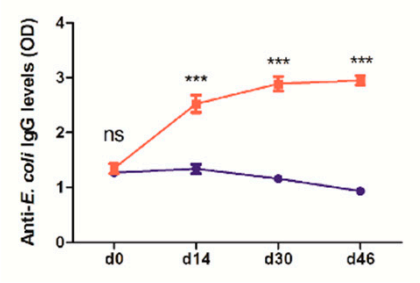

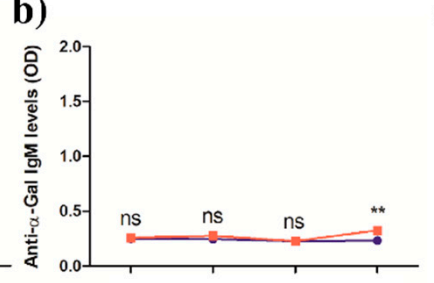

e)

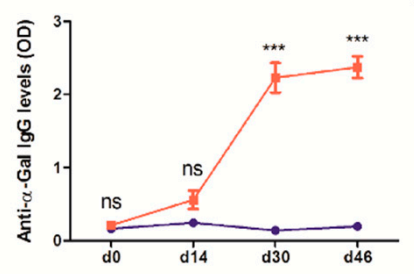

c)
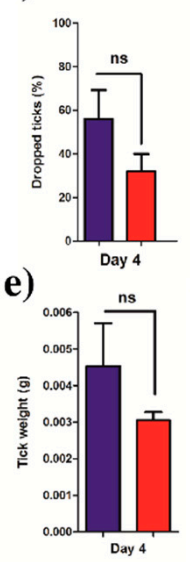

d)
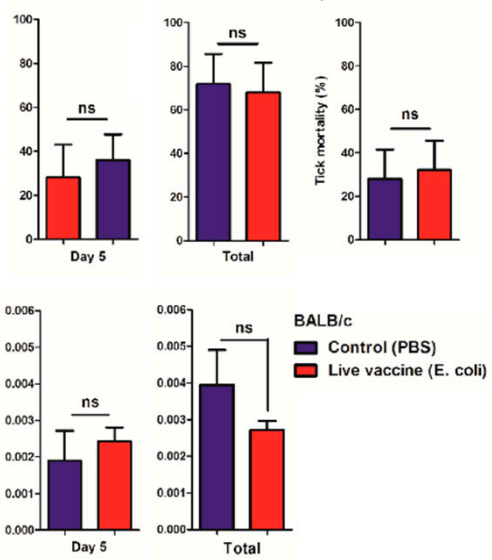

Figure 6. Antibody response of BALB/c mice and tick performance after $E$. coli immunization. The levels of IgM and IgG levels to (a) E. coli proteins and (b) $\alpha$-Gal were quantified in sera by ELISA. (c) The percentage of ticks that dropped on days 4 or 5 , and the total, were calculated and compared between groups. (d) The percentage of dead ticks was calculated and tick mortality (\%) compared between groups. (e) At the end of the feeding, the weight of individual ticks was measured and compared between groups. Means, standard error $(\mathbf{a}, \mathbf{b})$ and standard deviation (c-e) values are shown. Results were compared by two-way ANOVA with Bonferroni multiple comparison test applied for individual comparisons (ELISA) and Mann-Whitney U test (tick performance). ${ }^{* *} p<0.001,{ }^{* * *} p<0.0001$; ns-not significant; 1 experiment, $n=10$ mice ( $n=5$ ticks per mouse) and three technical replicates per sample (ELISA).

\subsection{Live E. coli Vaccination in $\alpha 1,3 G T$ KO Mice Is Associated with Decreased Relative Abundance of Enterobacteriaceae in I. ricinus}

We then asked whether vaccination with live $E$. coli was associated with changes in the abundance of Enterobacteriaceae bacteria in tick microbiota. Nymphs that fed on $\alpha 1,3 \mathrm{GT} \mathrm{KO}$ and BALB/c mice immunized with E. coli or mock vaccine, were left to molt to adults. After molting, ticks were pooled, the DNA extracted and the normalized levels of Enterobacteriaceae 16S were measured by qPCR. Total DNA was also extracted from engorged nymphs that fed on C57BL/6 mice. The results showed a significant decrease in the relative abundance of Enterobacteriaceae in adult ticks that had fed on E. coli-immunized $\alpha 1,3 \mathrm{GT} \mathrm{KO}$, compared to the control (Figure 7a). However, no significant changes in Enterobacteriaceae 16S abundance was found in the ticks that fed on either of the E. coli-immunized wild type strains, regardless of the developmental stage, unfed adults (BALB/c, Figure $7 \mathrm{~b}$ ) or fed nymphs (C57BL/6, Figure 7c). 
a)

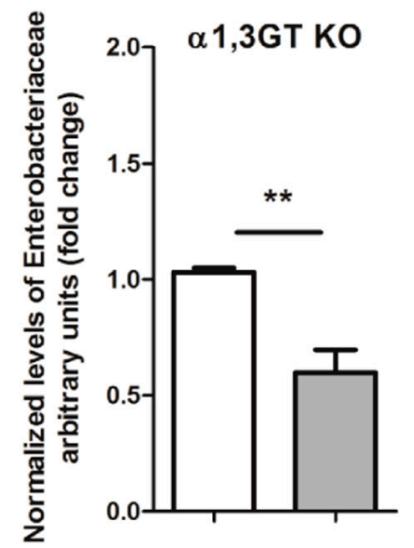

b)

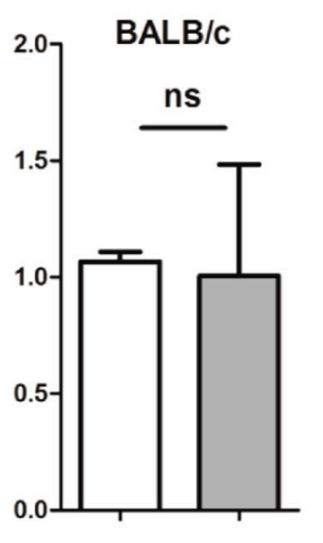

c)

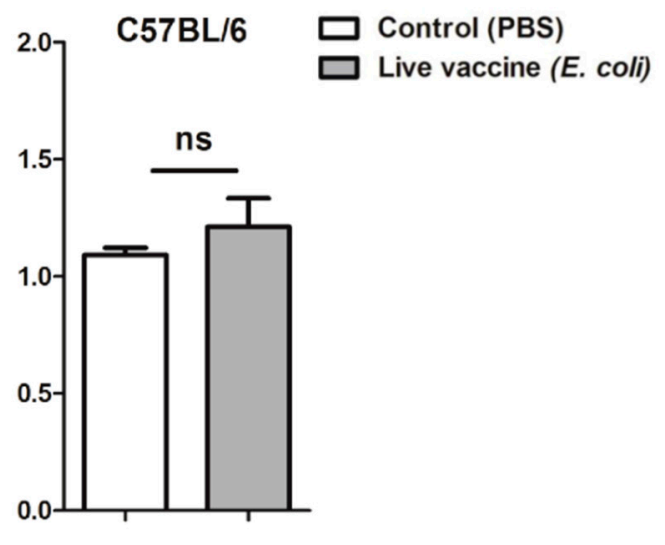

Figure 7. Relative abundance of Enterobacteriaceae in I. ricinus microbiota after feeding on E. coli-immunized mice. The relative abundance of Enterobacteriaceae was measured in adult ticks that in the previous stage (i.e., nymphs) had fed on (a) $\alpha 1,3 \mathrm{GT} \mathrm{KO}$ or (b) BALB/c and in engorged nymphs that fed on (c) C57BL/6 mice. Relative bacterial DNA levels were measured using Enterobacteriaceae-specific $16 \mathrm{~S}$ qPCR normalizing against tick $r s p 4$ with the $2^{-\Delta \Delta C t}$ ratio method. Results are relative to $16 \mathrm{~S}$ in the control group. Means and standard deviation values are displayed. Results were compared within each mouse strain by Mann-Whitney U test. (** $p<0.001$, ns-not significant; $n=11$ pools of ticks that fed $\alpha 1,3 \mathrm{GT}$ KO mice, $n=9$ pools of ticks that fed BALB/c, $n=18$ pools of ticks that fed C57BL/ 6 mice).

\section{Discussion}

Ticks harbor a high diversity of bacterial species, likely as part of their evolutionary strategy to cope with their complex lifecycle and metabolic deficiencies [38]. Evidence suggests that some bacteria have key roles in the structure, organization and functioning of tick microbiota, since they constitute a reduced taxonomic core of the tick gut microbiota that remains stable despite biological disturbance [5]. Most importantly, the ubiquitousness of these taxa is likely associated to benefits they provide to the microbial community or the host [4-6]. This phenomenon is extended in the microbiota of arthropods, with the presence of conserved functional groups, belonging to different classes of proteobacteria, with redundant metabolic capacities [39]. Microorganisms do not exist in isolation but form complex ecological interaction webs, with a positive, negative or no impact on the species involved [40,41]. A particularly important feature of any species is its ability to alter the abundance of other species and shape the whole community, which is referred as a species keystoneness [42]. Network models provide tools for understanding how the microbiota structure can influence host health [41,43-45]. Particularly, networks enable the simplified representation of microbial communities as nodes, representing interacting taxa, and links indicating co-occurrence [41]. Microbes that frequently co-occur with many others are referred to as keystone taxa and they play an important role in regulating the microbial community dynamics and functioning $[9,46]$. Centrality metrics are useful to assess the keystoneness of the nodes, although the centrality metrics best suited to assess keystoneness (i.e., closeness centrality and between centrality) are currently debated [7,46]. The eigenvector centrality (eigencentrality) was proposed as an alternative to closeness centrality and between centrality, since it represents the weighted sum of the centralities of all nodes that are connected to a given node [34]. A high eigenvector score indicates how well a node is connected to other well-connected nodes in the network [47]. In this study, we used three criteria, (i) eigencentrality, (ii) ubiquitousness, and (iii) the combination of relative abundance and eigencentrality, to identify keystone taxa within Ixodes microbiota. Despite the differences in the origin of Ixodes spp. used for analysis, bacteria of the family Enterobacteriaceae and Corynebacteriaceae were identified as keystone taxa of tick microbiota. 
Members of the family Enterobacteriaceae have been identified as keystone bacteria in vertebrate $[48,49]$ and plant $[50,51]$ microbiota.

Immunization of C57BL/6 mice with E. coli caused increased engorgement weight in $I$. ricinus nymphs. This suggests that $E$. coli, or other Enterobacteriaceae bacteria, may regulate tick feeding or that some metabolites produced by these bacteria may be negative regulators of tick feeding. Enterobacteriaceae may also influence the tick microbial community by ecological cooperation with beneficial bacteria and/or competition with deleterious bacteria. In agreement with this idea, the network analysis revealed positive and negative relationships between bacteria of Enterobacteriaceae and other bacteria present in tick microbiota. Interestingly, a previous study reported that $I$. scapularis larvae that engorged on gentamicin-treated $\mathrm{C} 3 \mathrm{H} / \mathrm{HeJ}$ mice demonstrated significantly increased engorgement weights, and decreased B. burgdorferi colonization when compared to larvae that fed on buffer-treated mice [52]. Gentamicin is active against a wide range of bacterial species, including Gram-negative bacteria of the family Enterobacteriaceae, and the Gram-positive Staphylococcus. Altogether, these observations suggest that decreasing the abundance of E. coli by immune targeting or antibiotic treatment influences tick feeding by an as yet unknown mechanism. However, it is noteworthy that no changes in the abundance of Enterobacteriaceae was observed in engorged I. ricinus nymphs that fed on E. coli-immunized C57BL/6 mice.

The fact that ticks that fed on E. coli-immunized BALB/c mice did not show an increased engorgement weight as C57BL/6, suggests that host genetic factors or differences in host microbiota may influence the effect of the anti-tick microbiota vaccination based on E. coli. The two non-transgenic mice strains used in our study, $\mathrm{C} 57 \mathrm{BL} / 6$ and $\mathrm{BALB} / \mathrm{c}$, exhibited great differences in gut microbiota [53], and differences in gut microbiota in genetically identical mice explained diverse susceptibilities to vector-borne infections such as malaria [54]. Alternatively, the lack of anti-E. coli IgM response in $\mathrm{BALB} / \mathrm{c}$ may have limited the impact of the vaccination on Enterobacteriaceae and/or the ticks.

Immunization with E. coli caused high mortality in I. ricinus nymphs that fed on $\alpha 1,3 \mathrm{GT} \mathrm{KO}$, but not in the ticks fed on C57BL/ 6 or BALB/c mice. Of the mouse strains used in this study, only $\alpha 1,3 \mathrm{GT}$ $\mathrm{KO}$ developed both anti-E. coli and anti- $\alpha-G a l$ IgM and IgG in response to E. coli immunization, while C57BL/6 and BALB/c failed to produce high levels of IgG to $\alpha-G a l$ (C57BL/6) or IgM to E. coli and $\alpha-\mathrm{Gal}(\mathrm{BALB} / \mathrm{c})$. In addition, a significant reduction in the abundance of Enterobacteriaceae was observed only in E. coli-immunized $\alpha 1,3 \mathrm{GT}$ KO. Host IgM and IgG induced by E. coli immunization may recognize and bind the E. coli within the tick microbiota and kill the bacteria. Outer surface protein (OspA) antibodies were shown to kill Borrelia burgdorferi spirochetes within feeding nymphs and block transmission to mice in a complement-independent manner [55]. A similar mechanism may account for E. coli killing by specific antibodies. The results suggest that in addition to antibodies to E. coli proteins, anti- $\alpha-G a l$ immunity may protect against tick infestation.

In this study, however, we could not unravel whether the anti- $\alpha$-Gal antibodies could also target tick proteins carrying $\alpha$-Gal. Since the proposal that tick $\alpha$-Gal was the molecular trigger of the $\alpha$-Gal syndrome [56], the detection of $\alpha$-Gal in ticks has been a focus of research. Previous studies reported the presence of $\alpha-\mathrm{Gal}$ in I. ricinus [57] and I. scapularis [58] midguts and salivary gland proteins of Haemaphysalis longicornis [59], Amblyomma sculptum [60] and Amblyomma americanum [58]. Tick proteins with the $\alpha$-Gal modification were also detected and characterized in salivary gland extracts of Rhipicephalus bursa, Rhipicephalus microplus and Hyalomma marginatum [30,61]. The enzymes required for the early and late steps of the N-glycosylation pathway [31] and $\alpha$-Gal synthesis [19] were identified in ticks, suggesting that these arthropods produce endogenous $\alpha$-Gal. The synthesis of $\alpha$-Gal by ticks and the presence of this modification in tick salivary proteins may be a mechanism of molecular mimicry to escape the immune response of vertebrate hosts producing endogenous $\alpha$-Gal and incapable of producing natural anti- $\alpha$-Gal antibodies [19,31]. The introduction of tick saliva with $\alpha-G a l$ in the human skin through tick bites may trigger a strong immune response to this glycan resulting in allergic reactions and rupture of oral tolerance to this carbohydrate [28]. As previously 
proposed [62], the ability to produce anti- $\alpha$-Gal antibodies could make the human a nonsusceptible host to tick infestations.

In this study, we provided for the first time evidence of the genetic basis of $\alpha$-Gal production by tick microbiota bacteria. Overall, six different $\alpha 1$,3-galactosyltransferase genes were predicted to be present in several bacterial families of the tick gut microbiome, which suggests that tick microbiota could be considered as an additional source of $\alpha$-Gal in ticks. This finding was confirmed by PCR and sequencing. Enterobacteriaceae, and other bacterial families express $\alpha 1,3$-galactosyltransferase genes and synthetize $\alpha$-Gal in the human gut microbiome [24]. The production of $\alpha$-Gal by tick gut microbiota raises the possibility that bacterial molecules containing $\alpha$-Gal may be introduced to the host through the tick saliva triggering allergic reactions in humans or immune escape in noncatarrhine mammalian hosts.

\section{Conclusions}

In this study, we showed that keystone bacteria of the tick gut microbiota play important roles in tick physiology during feeding and that $\alpha 1,3$-galactosyltransferase genes are widely distributed in the microbiome of I. scapularis and I. ricinus. Targeting specific vector microbiota bacteria with host antibodies appears to be a suitable tool for the experimental manipulation of the vector microbiota, with implications for studies on vector physiology, control and potentially vector competence for pathogen transmission. Vaccination with E. coli induced an antibody response against bacterial proteins and $\alpha$-Gal. The presence of high levels of anti-E. coli and anti- $\alpha$-Gal IgM and IgG seems to be necessary to induce tick mortality. This antibody response correlated with reduction of tick infestations, likely affecting tick fitness due to a direct effect on commensal microbiota bacteria with $\alpha$-Gal and to direct action against tick proteins with this modification. The results of this study warrant further experiments to characterize the role of anti- $\alpha-G a l$ immunity in protection against tick infestation and pathogen transmission. The approach described in this study opens up the possibility of using live-bacteria vaccination to target keystone bacteria and study the function of specific members of gut microbiota.

\section{Materials and Methods}

\subsection{Screenings of Central Bacteria in Tick Gut Microbiota of I. scapularis and I. ricinus Nymphs}

\subsubsection{Original 16S Data Sets}

In the first step of the study, we used published $16 \mathrm{~S}$ datasets. The original studies described the taxonomic composition of the gut microbiomes of nymphs of I. scapularis and I. ricinus ticks grown in different conditions in the USA and Europe, respectively (detailed below). These datasets were generated by 251-base paired-end reads from amplicon sequencing of the V4 variable region of the bacterial $16 \mathrm{~S}$ gene, using barcoded universal primers $(515 \mathrm{~F} / 806 \mathrm{R})$, sequenced on an Illumina MiSeq system.

(i) The I. scapularis data set was described by Abraham et al. [32]. They studied the changes in gut microbiota composition and biofilms of nymphs of I. scapularis fed on A. phagocytophilum-infected or not infected $\mathrm{C} 3 \mathrm{H} / \mathrm{HeJ}$ mice housed in laboratory conditions at Yale University, USA. From this data set we used only the samples from nymph fed on uninfected mice $(n=10)$.

(ii) The I. ricinus $16 \mathrm{~S}$ data set was described by Aivelo et al. [33]. They collected free-living ticks from different life stages at three locations in the Swiss Alps, Kanton Graubünden, Switzerland, encompassing a gradient of three heights above sea level. From this data set we only considered the samples representing nymphs $(n=10)$. 


\subsubsection{Processing of Original Raw Sequences}

The raw sequences were downloaded from SRA repository [63], extracted, and de-interlaced in two fastq datasets containing the mate read [64] using the data analysis platform Galaxy (http: //usegalaxy.org). The sequences were analyzed using QIIME 2 pipeline (v. 2019.1) [65]. The fastq files were denoised and merged using DADA2 software [66] implemented in QIIME 2. The amplicon sequence variants (ASVs) were aligned with MAFFT [67] (via q2-alignment) and used to construct a phylogeny with FastTree 2 [68] (via q2-phylogeny). Taxonomy was assigned to ASVs using a classify-sklearn naïve Bayes taxonomic classifier [69] based on SILVA database (release 132) [70], only the target sequences fragment was used in the classifier (i.e., classifier trained with the primers) [71,72]. The ubiquitousness of the bacterial families was addressed in each data set by identifying the taxa that persisted across serial fractions of the samples, performed with the QIIME 2 plugin feature-table (core-features) [65].

\subsubsection{Bacterial Co-Occurrence Networks}

Co-occurrence networks were constructed for each dataset, based on taxonomic profiles, collapsed at family level. The SparCC method [73] implemented in the R environment was used to calculate the correlations matrix. The topological parameter of the networks (i.e., number of nodes and edges, weighted degree, diameter of the network, modularity, and clustering coefficient) were calculated in each data set. Furthermore, we explored the centrality metrics (i.e., betweenness centrality, harmonic centrality, and closeness centrality) [34] for measure the keystoneness of each node, and selected eigenvector centrality for the analysis because it takes into account both the number of connections of a given node and its relevance in terms of influence within the network [47]. Calculations and network visualizations were done with the software Gephi 0.9.2 [74].

\subsubsection{Prediction of Functional Traits in Tick Microbiome}

The $16 \mathrm{~S}$ amplicon sequences from each data set were used to predict the metabolic profiling of each sample. PICRUSt2 [36] was used to predict the metagenomes from $16 \mathrm{~S}$ amplicon sequences. Briefly, the AVSs were placed into a reference tree (NSTI cut-off value of 2) contained 20,000 full 16S sequences from prokaryotic genomes, which is then used to predict individual gene family copy numbers for each AVS. The predictions are based on Kyoto Encyclopedia of Genes and Genomes (KEGG) orthologs (KO) [75].

\subsubsection{Identification of $\alpha-1,3-$ Galactosyltransferase Genes in Tick Microbiota Bacteria}

The presence of the selected $\alpha$-1,3-galactosyltransferase genes in bacteria residing tick midguts was confirmed by conventional PCR and sequencing. Prior to tick dissection and genomic DNA extraction, 25 I. ricinus female ticks obtained from a laboratory colony (Institute of Parasitology, University of Veterinary Medicine Vienna, Austria) were surface-sterilized with successive washes with $3 \%$ hydrogen peroxide, $70 \%$ ethanol, and double-distilled water to remove environmental contaminants. Tick midguts were dissected by sterile blades, pooled (five ticks per pool), homogenized, and DNA was extracted using the peqGOLD TriFast DNA extraction procedure (Peqlab, Erlangen, Germany). The bacterial $\alpha-1,3$-galactosyltransferase genes were amplified using designed primers based on nucleotide sequences available in the KEGG database (K02450, K02847, K03275, K03276, and K03279). DNA extracted from cat feces served as positive control in each PCR run. The primer sequences and PCR amplification conditions are shown in Table 2. Generated PCR products were separated by electrophoresis in 2\% agarose gels stained with Midori Green Advance DNA stain (Nippon Genetics Europe, Germany). All positive samples were purified and sequenced in both directions by a commercial company (LGC Genomics, Berlin, Germany). Obtained nucleotide sequences were edited using the software BioEdit (www.mbio.ncsu.edu/BioEdit/bioedit.html) and compared for similarity to sequences available in GenomeNet using BLASTN analysis (https://www.genome.jp/tools/blast/). 
Table 2. Primers and PCR conditions used for amplification of $\alpha-1,3$-galactosyltransferase genes from midgut bacteria of Ixodes ricinus ticks.

\begin{tabular}{|c|c|c|c|}
\hline $\begin{array}{c}\text { Gene Names } \\
\text { (Reference Accessions) }\end{array}$ & $\begin{array}{l}\text { Primer Sequences } \\
\qquad\left(5^{\prime}-3^{\prime}\right)\end{array}$ & $\begin{array}{l}\text { Annealing Temperature } \\
\qquad\left({ }^{\circ} \mathrm{C}\right)\end{array}$ & $\begin{array}{l}\text { Fragment Length } \\
\text { (bp) }\end{array}$ \\
\hline \multirow{2}{*}{$g s p A(\mathrm{~K} 02450)$} & $\begin{array}{c}\text { 1. reaction } \\
\text { gspA_F: GTTGGGTGAGGCTGGAAGTG } \\
\text { gspA_R: TGCGATCCAGGGCAAATTCTG }\end{array}$ & 60 & 958 \\
\hline & $\begin{array}{c}\text { 2. reaction (nested) } \\
\text { gspAnest_F: TGAATCACCGCCGCATACT } \\
\text { gspAnest_R: CTCATCACCACGGCAAGCT }\end{array}$ & 58 & 406 \\
\hline waaL, rfaL (K02847) & $\begin{array}{l}\text { waaL_F: CAATGCATATCGTGGCCCAA } \\
\text { waaL_R: CCGACTGAAGTTCTGGTGTT }\end{array}$ & 58 & 573 \\
\hline waaO, rfaI (K03275) & $\begin{array}{l}\text { waaO_F: GAACGGCTTAAGGCATTACC } \\
\text { waaO_R: CTTGGCGCAATAACGAGCA }\end{array}$ & 56 & 654 \\
\hline waaR, waaT and rfaJ (K03276) & $\begin{array}{l}\text { waaR_F: GTACACAGGTCTGGTCAAGA } \\
\text { waaR_R: CAGACTCCTGCTATAATTCCTG }\end{array}$ & 56 & 685 \\
\hline waaJ and rfaJ (K03279) & $\begin{array}{c}\text { waaJ_F: CCGTTAAACTTGATGAACGGGAA } \\
\text { waaJ_R: TAGTTCGCCCAATCATGCCA }\end{array}$ & 60 & 748 \\
\hline
\end{tabular}




\subsection{Experimental Procedures}

\subsubsection{Ethics Statement}

All procedures in this work were performed according to the principles established by the French and International Guiding Principles for Biomedical Research Involving Animals (2012) at the French Agency for Food, Environmental and Occupational Health \& Safety (ANSES) accredited animal facilities in Maisons-Alfort, France. Ethics Committee for Animal Experiments approbation: ComEth Anses/ENVA/UPEC, Permit Numbers E 9404608.

\subsubsection{Mice and Housing Conditions}

BALB/cByJ (Charles River strain code 028) and C57BL/6 (Charles River strain code 027) mice were purchased from Charles River (Miserey, France). The ggta1 gene knockout mice ( $\alpha 1,3 \mathrm{GT}$ KO mice) were bred in a colony maintained at the French Agency for Food, Environmental and Occupational Health \& Safety (ANSES) accredited animal facilities in Maisons-Alfort, France. The breeding pairs of $\alpha 1,3 \mathrm{GT}$ KO mice were kindly donated by Dr. Florian Wölbing (Department of Dermatology, Technical University of Munich, Germany). $\alpha 1,3 \mathrm{GT}$ KO mice do not synthesize $\alpha$-Gal and produce natural anti- $\alpha$-Gal Abs in titers similar to those in humans, and have been successfully used to test the protective capacity of these antibodies in models of malaria and leishmaniosis [21,76,77]. Six-week-old $\alpha 1,3 \mathrm{GT}$ KO mice from a colony maintained at the French Agency for Food, Environmental and Occupational Health \& Safety (ANSES) accredited animal facilities in Maisons-Alfort, France, were used. The animals were maintained in Green line ventilated racks (Tecniplast, Hohenpeissenberg, Germany) at $-20 \mathrm{~Pa}$,) with food (Kliba nafaj, Rinaustrasse, Switzerland) and water offered ad libitum. The photoperiod cycles (12 $\mathrm{h}$ per day) and room temperature $\left(20-23^{\circ} \mathrm{C}\right)$ were controlled. The animals were monitored twice a day by an experienced technician for any abnormal skin reactions, health problems or complications.

\section{Bacteria Culture and Life Bacteria Immunization}

The bacteria E. coli BL21 (DE3, Invitrogen, Carlsbad, CA, USA) were grown on $50 \mathrm{~mL}$ of Luria Broth (Sigma-Aldrich, St. Louis, MO, USA), at $37{ }^{\circ} \mathrm{C}$ to $\mathrm{OD}_{600}=0.8$. The bacteria were washed twice with phosphate buffer saline (PBS): $10 \mathrm{mM} \mathrm{NaH}_{2} \mathrm{PO}_{4}, 2.68 \mathrm{mM} \mathrm{KCl}, 140 \mathrm{mM} \mathrm{NaCl}, \mathrm{pH} 7.2$ (Thermo Scientific, Waltham, MA, USA), centrifuged at $1000 \times g$ for $5 \mathrm{~min}$ at $4{ }^{\circ} \mathrm{C}$, resuspended in PBS at $3.6 \times 10^{4}$ colony-forming unit (CFU)/mL and homogenized with 20 strokes using a glass homogenizer. All reagents used for bacterial preparation were apyrogenic. Six-week-old $\alpha 1,3 \mathrm{GT}$ KO $(n=6), \mathrm{C} 57 \mathrm{BL} / 6(n=5)$ and BALB/c $(n=5)$ mice were immunized subcutaneously with E. coli in 100 $\mu \mathrm{L}\left(1 \times 10^{6} \mathrm{CFU}\right)$ of a water-in-oil emulsion containing 70\% Montanide ISA71 VG adjuvant (SEPPIC, Castres, France), with a booster dose on day 14, two weeks after the first dose. Control $\alpha 1,3 \mathrm{GT}$ KO $(n=6), \mathrm{C} 57 \mathrm{BL} / 6(n=5), \mathrm{BALB} / \mathrm{c}(n=5)$ mice received a mock vaccine containing PBS and adjuvant.

\section{Sera Collection and Preparation}

Blood samples were collected on days $0,14,30$ and 46 on sterile tubes without anticoagulant. For serum separation, the blood samples were incubated for $2 \mathrm{~h}(\mathrm{~h})$ at room temperature (RT), allowing for clotting, and then centrifuged at $5000 \times g$ for $5 \mathrm{~min}$ at RT, twice.

\section{Tick Infestation}

Twenty-six days after the second immunization, each mouse was infested with five ( $\alpha 1,3 \mathrm{GT}$ KO and BALB/c) and twenty (C57BL/6) I. ricinus nymphs. The ticks were obtained from the colonies of UMR-BIPAR, Maisons-Alfort, France. Ticks were fed on experimental mice within the EVA-foam (Cosplay Shop, Brugge, Belgium) capsule glued to the animal backs [78]. Engorged nymphs were kept in a polypropylene tube and maintained with a light-dark (12 h/12 h) cycle in a glass desiccator with $>97 \%$ relative humidity at $22{ }^{\circ} \mathrm{C}$. 


\section{Protein Extraction}

The E. coli was washed twice with PBS, centrifuged at $1000 \times g$ for 5 min at $4{ }^{\circ} \mathrm{C}$, resuspended in $7 \mathrm{M}$ Urea lysis buffer (Sigma-Aldrich, St. Louis, MO, USA) and homogenized with 20 strokes using a glass balls homogenizer. The homogenate was centrifuged at $300 \times g$ for $5 \mathrm{~min}$ at $4{ }^{\circ} \mathrm{C}$ and the supernatant was collected. Protein concentration was determined using the Bradford Protein Assay (Thermo Scientific, San Jose, CA, USA) with Bovine Serum Albumin (BSA) as standard.

\section{Indirect ELISA for Anti- $\alpha$-Gal and Anti-BL21 Protein Antibodies}

To evaluate the levels of specific Abs against Gal $\alpha 1-3 \mathrm{Gal}$ ( $\alpha-\mathrm{Gal}$ ), and E. coli protein extract as protocols previously published were used [15-17,23], with slight modifications. The 96-well ELISA plates (Thermo Scientific, Waltham, MA, USA) were coated with $0.5 \mu \mathrm{g} / \mathrm{mL}$ ( $100 \mu \mathrm{L} /$ well) of either Gal $\alpha 1-3$ Gal linked to BSA (Dextra Laboratories, Reading, UK) or E. coli protein extract and incubated for $2 \mathrm{~h}$ with $100 \mathrm{rpm}$ shaking at room temperature. Subsequently, plates were incubated overnight at $4{ }^{\circ} \mathrm{C}$. The antigens were diluted in carbonate/bicarbonate buffer $(0.05 \mathrm{M}, \mathrm{pH} 9.6)$ and incubated overnight at $4{ }^{\circ} \mathrm{C}$. Optimal antigen concentration and dilutions of sera and conjugate were defined using a titration assay. Wells were washed three times with $100 \mu \mathrm{L}$ of PBS containing $0.05 \%$ (vol/vol) Tween 20 (PBST), and then blocked by adding $100 \mu \mathrm{L}$ of 1\% Human Serum Albumin (HSA)/PBS for $1 \mathrm{~h}$ at RT and $100 \mathrm{rpm}$ shaking. After three washes, serum samples, diluted in 0.5\% HSA/PBS (1:50 or 1:500 for BALB/c mice), were added to the wells and incubated for $1 \mathrm{~h}$ at $37^{\circ} \mathrm{C}$ with shaking. The plates were washed three times and HRP-conjugated Abs (goat anti-mice IgG and IgM) (Sigma-Aldrich, St. Louis, MO, USA) were added at 1:1500 dilution in 0.5\% HSA/PBST (100 $\mu \mathrm{L} /$ well $)$ and incubated for $1 \mathrm{~h}$ at RT with shaking. The plates were washed three times and the reaction was developed with $100 \mu \mathrm{L}$ ready-to-use TMB solution (Promega, Madison, WI, USA) at RT for $20 \mathrm{~min}$ in the dark, and then stopped with $50 \mu \mathrm{L}$ of $0.5 \mathrm{M} \mathrm{H} 2 \mathrm{SO}$. The OD values were measured at $450 \mathrm{~nm}$ using an ELISA plate reader (Filter-Max F5, Molecular Devices, San Jose, CA, USA). All samples were tested in triplicate and the average value of three blanks (no Abs) was subtracted from the reads. The cut-off was determined as two times a mean OD value of the blank controls.

\section{Relative Quantification of Enterobacteriaceae by qPCR}

\subsection{DNA Extraction}

DNA was extracted from nymphs that fed on C57BL/6 and the nymphs that fed on $\alpha 1,3 \mathrm{GT}$ KO and BALB/c were allowed to molt to adults. Nymphs and adults were pooled ( $n=5$ ticks per pool) and crushed with glass beads using a Precellys24 Dual homogeniser (Bertin technologies, Paris, France) at $5500 \times$ rpm for $20 \mathrm{~s}$. Genomic DNA was then extracted using a Nucleospin tissue DNA extraction Kit (Macherey-Nagel, Hoerdt, France). For each sample, total DNA was eluted in $75 \mu \mathrm{l}$ of sterile water and stored at $-20^{\circ} \mathrm{C}$ until further analysis.

\section{2. $q P C R$}

To quantify the relative amount of Enterobacteriaceae bacteria, a qPCR was carried out using primers and protocol previously reported [79]. A 16S rRNA gene amplification was performed with SYBR Green LightCycler 480 Master mix (Roche, Meylan, France) and the conditions as follow: $50{ }^{\circ} \mathrm{C}$ for $2 \mathrm{~min}, 95^{\circ} \mathrm{C}$ for $10 \mathrm{~min}, 40$ cycles of $95^{\circ} \mathrm{C}$ for $15 \mathrm{~s}$ and $60^{\circ} \mathrm{C}$ for $1 \mathrm{~min}$. The $\mathrm{CT}$ values were recorded, and the relative levels of bacterial DNA were normalized against tick $r s p 4$ as housekeeping gene. Fold change in relative quantities were then calculated using the $2^{-\Delta \Delta \mathrm{Ct}}$ ratio method [80].

\section{Statistical Analysis}

Differences in antibody levels (OD) between groups in the different time points were evaluated using two-way ANOVA with Bonferroni multiple comparison test applied for individual comparisons. 
Unpaired non-parametric Mann-Whitney $U$ test was used to compare the tick parameters and Enterobacteriaceae levels between groups. All analyses were performed in the GraphPad 5 Prism program (GraphPad Software Inc., San Diego, CA, USA). Differences were considered significant when $p<0.05$.

Supplementary Materials: The following are available online at http://www.mdpi.com/2076-393X/8/4/702/s1, Table S1. Values of eigencentrality and relative abundance of bacteria taxa in I. scapularis and I. ricinus microbiota.

Author Contributions: L.M.-H., D.O., J.M., J.d.1.F. and A.C.-C.; Formal analysis, L.M.-H., D.O., A.E.-P., A.H. and A.C.-C.; Investigation, L.M.-H., D.O., J.M, J.B, A.H. and L.Š.; Methodology, J.M., A.E.-P., D.O, L.Š. and A.C.-C.; Resources, N.V. and A.C.-C.; Supervision, A.C.-C.; Visualization, D.O. and A.C.-C.; Writing-original draft, L.M.-H., D.O. and A.C.-C.; Writing—review \& editing, L.M.-H., D.O., J.M., N.V., J.d.I.F., A.E.-P., A.H., L.Š., J.B. and A.C.-C. All authors have read and agreed to the published version of the manuscript.

Funding: This research received no external funding.

Acknowledgments: Authors would like to thank Josef Harl (University of Veterinary Medicine Vienna, Austria) for his help with the primers design. We also thank members of our laboratories for fruitful discussions on this manuscript.

Conflicts of Interest: The authors declare no conflict of interest.

\section{References}

1. Duron, O.; Morel, O.; Bouchez, O.; Buysse, M.; Binetruy, F.; Lancelot, R.; Loire, E.; Ménard, C.; Bouchez, O.; Vavre, F.; et al. Tick-Bacteria Mutualism Depends on B Vitamin Article Tick-Bacteria Mutualism Depends on B Vitamin Synthesis Pathways. Curr. Biol. 2018, 28, 1896-1902. [CrossRef] [PubMed]

2. Narasimhan, S.; Fikrig, E. Tick microbiome: The force within. Trends Parasitol. 2015, 31, 315-323. [CrossRef] [PubMed]

3. Smith, T.A.; Driscoll, T.; Gillespie, J.J.; Raghavan, R.A. Coxiella-like endosymbiontis a potential vitamin source for the lone star tick. Genome Biol. Evol. 2015, 7, 831-838. [CrossRef] [PubMed]

4. Obregón, D.; Bard, E.; Abrial, D.; Cabezas-Cruz, A. Sex-Specific Linkages between Taxonomic and Functional Profiles of Tick Gut Microbiomes. Front. Cell Infect. Microbiol. 2019, 9, 298. [CrossRef]

5. Estrada-Peña, A.; Cabezas-Cruz, A.; Obregón, D. Resistance of tick gut microbiome to anti-tick vaccines, pathogen infection and antimicrobial peptides. Pathogens 2020, 9, 309. [CrossRef]

6. Díaz-Sánchez, S.; Estrada-Peña, A.; Cabezas-Cruz, A.; de la Fuente, J. Evolutionary Insights into the Tick Hologenome. Trends Parasitol. 2019, 35, 725-737. [CrossRef]

7. Banerjee, S.; Schlaeppi, K.; van der Heijden, M.G.A. Keystone taxa as drivers of microbiome structure and functioning. Nat. Rev. Microbiol. 2018, 16, 567-576. [CrossRef]

8. Weiss, S.; Van Treuren, W.; Lozupone, C.; Faust, K.; Friedman, J.; Deng, Y.; Xia, L.C.; Xu, Z.Z.; Ursell, L.; $\mathrm{Alm}$, E.J.; et al. Correlation detection strategies in microbial data sets vary widely in sensitivity and precision. ISME J. 2016, 10, 1669-1681. [CrossRef]

9. Herren, C.M.; McMahon, K.D. Keystone taxa predict compositional change in microbial communities. Environ. Microbiol. 2018, 20, 2207-2217. [CrossRef]

10. Galili, U.; Mandrell, R.E.; Hamadeh, R.M.; Shohet, S.B.; Griffiss, J.M. Interaction between human natural anti-alpha-galactosyl immunoglobulin G and bacteria of the human flora. Infect. Immun. 1988, 56, 1730-1737. [CrossRef]

11. Hamadeh, R.M.; Jarvis, G.A.; Zhou, P.; Griffiss, J.M. Bacterial enzymes can add galactose alpha 1,3 to human erythrocytes and creates a senescence-associated epitope. Infect. Immun. 1996, 64, 528-534. [CrossRef] [PubMed]

12. Chen, C.; Liu, B.; Xu, Y.; Utkina, N.; Zhou, D.; Danilov, L.; Torgov, V.; Veselovsky, V.; Feng, L. Biochemical characterization of the novel $\alpha-1,3$-galactosyltransferase WclR from Escherichia coli O3. Carbohydr. Res. 2016, 430, 36-43. [CrossRef] [PubMed]

13. Pradel, E.; Parker, C.T.; Schnaitman, C.A. Structures of the $r f a B, r f a I, r f a J$, and $r f a S$ genes of Escherichia coli K-12 and their roles in assembly of the lipopolysaccharide core. J. Bacteriol. 1992, 174, 4736-4745. [CrossRef] [PubMed] 
14. Ohashi, T.; Fujiyama, K.; Takegawa, K. Identification of novel $\alpha 1,3$-galactosyltransferase and elimination of $\alpha$-galactose-containing glycans by disruption of multiple $\alpha$-galactosyltransferase genes in Schizosaccharomyces pombe. J. Biol. Chem. 2012, 287, 38866-38875. [CrossRef] [PubMed]

15. Mateos-Hernández, L.; Risco-Castillo, V.; Torres-Maravilla, E.; Bermúdez-Humarán, L.G.; Alberdi, P.; Hodžić, A.; Hernández-Jarguin, A.; Rakotobe, S.; Galon, C.; Devillers, E.; et al. Gut Microbiota Abrogates Anti- $\alpha$-Gal IgA Response in Lungs and Protects against Experimental Aspergillus Infection in Poultry. Vaccines 2020, 8, 285. [CrossRef]

16. Hodžić, A.; Mateos-Hernández, L.; Fréalle, E.; Román-Carrasco, P.; Alberdi, P.; Pichavant, M.; Risco-Castillo, V.; Le Roux, D.; Vicogne, J.; Hemmer, W.; et al. Infection with Toxocara canis Inhibits the Production of IgE Antibodies to $\alpha$-Gal in Humans: Towards a Conceptual Framework of the Hygiene Hypothesis? Vaccines 2020, 8, 167. [CrossRef] [PubMed]

17. Galili, U.; Shohet, S.B.; Kobrin, E.; Stults, C.L.; Macher, B.A. Man, apes, and Old World monkeys differ from other mammals in the expression of alpha-galactosyl epitopes on nucleated cells. J. Biol. Chem. 1988, 263, 17755-17762. [PubMed]

18. Hennet, T. The galactosyltransferase family. Cell Mol. Life Sci. 2002, 59, 1081-1095. [CrossRef]

19. Cabezas-Cruz, A.; Espinosa, P.J.; Alberdi, P.; Šimo, L.; Valdés, J.J.; Mateos-Hernández, L.; Contreras, M.; Villar Rayo, M.; de la Fuente, J. Tick galactosyltransferases are involved in $\alpha$-Gal synthesis and play a role during Anaplasma phagocytophilum infection and Ixodes scapularis tick vector development. Sci. Rep. 2018, 8, 1-18. [CrossRef]

20. Jennings, M.P.; Virji, M.; Evans, D.; Srikhanta, Y.N.; Steeghs, L.; van der Ley, P.; Moxon, E.R. Identification of a novel gene involved in pilin glycosylation in Neisseria meningitidis. Mol. Microbiol. 1998, 29, 975-984. [CrossRef]

21. Yilmaz, B.; Portugal, S.; Tran, T.M.; Gozzelino, R.; Ramos, S.; Gomes, J.; Regalado, A.; Cowan, P.J.; d'Apice, A.J.F.; Chong, A.S.; et al. Gut microbiota elicits a protective immune response against malaria transmission. Cell 2014, 159, 1277-1289. [CrossRef] [PubMed]

22. Galili, U. Evolution in primates by "Catastrophic-selection" interplay between enveloped virus epidemics, mutated genes of enzymes synthesizing carbohydrate antigens, and natural anti-carbohydrate antibodies. Am. J. Phys. Anthropol. 2019, 168, 352-363. [CrossRef] [PubMed]

23. Pacheco, I.; Contreras, M.; Villar, M.; Risalde, M.A.; Alberdi, P.; Cabezas-Cruz, A.; Gortázar, C.; de la Fuente, J. Vaccination with Alpha-Gal Protects Against Mycobacterial Infection in the Zebrafish Model of Tuberculosis. Vaccines 2020, 8, 195. [CrossRef] [PubMed]

24. Montassier, E.; Al-Ghalith, G.A.; Mathé, C.; Le Bastard, Q.; Douillard, V.; Garnier, A.; Guimon, R.; Raimondeau, B.; Touchefeu, Y.; Duchalais, E.; et al. Distribution of Bacterial $\alpha 1,3-$ Galactosyltransferase Genes in the Human Gut Microbiome. Front. Immunol. 2020, 10, 3000. [CrossRef] [PubMed]

25. Galili, U.; Clark, M.R.; Shohet, S.B.; Buehler, J.; Macher, B.A. Evolutionary relationship between the natural anti-Gal antibody and the Gal alpha 1-3Gal epitope in primates. Proc. Natl. Acad. Sci. USA 1987, 84, 1369-1373. [CrossRef]

26. Macher, B.A.; Galili, U. The Galalpha1,3Galbeta1,4GlcNAc-R (alpha-Gal) epitope: A carbohydrate of unique evolution and clinical relevance. Biochim. Biophys. Acta 2008, 1780, 75-88. [CrossRef] [PubMed]

27. Van Nunen, S.; O'Connor, K.S.; Clarke, L.R.; Clarke, L.R.; Boyle, R.X. The association between Ixodes holocyclus tick bite reactions and red meat allergy. Intern. Med. J. 2007, 39, A132.

28. Cabezas-Cruz, A.; Hodžić, A.; Román-Carrasco, P.; Mateos-Hernández, L.; Duscher, G.G.; Sinha, D.K.; Hemmer, W.; Swoboda, I.; Estrada-Peña, A.; de la Fuente, J. Environmental and Molecular Drivers of the $\alpha$-Gal Syndrome. Front. Immunol. 2019, 10, 1210. [CrossRef]

29. Platts-Mills, T.A.E.; Commins, S.P.; Biedermann, T.; van Hage, M.; Levin, M.; Beck, L.A.; Diuk-Wasser, M.; Jappe, U.; Apostolovic, D.; Minnicozzi, M.; et al. On the cause and consequences of $\operatorname{IgE}$ to galactose- $\alpha$-1,3-galactose: A report from the National Institute of Allergy and Infectious Diseases Workshop on Understanding IgE-Mediated Mammalian Meat Allergy. J. Allergy Clin. Immunol. 2020, 145, 1061-1071. [CrossRef]

30. Mateos-Hernández, L.; Villar, M.; Moral, A.; García Rodríguez, C.; Alfaya Arias, T.; de la Osa, V.; Feo Brito, F.; Fernández de Mera, I.G.; Alberdi, P.; Ruiz-Fons, F.; et al. Tick-host conflict: Immunoglobulin E antibodies to tick proteins in patients with anaphylaxis to tick bite. Oncotarget 2017, 8, 20630-20644. [CrossRef] 
31. Park, Y.; Kim, D.; Boorgula, G.D.; De Schutter, K.; Smagghe, G.; Šimo, L.; Archer-Hartmann, S.A.; Azadi, P. Alpha-Gal and Cross-Reactive Carbohydrate Determinants in the N-Glycans of Salivary Glands in the Lone Star Tick, Amblyomma americanum. Vaccines 2020, 8, 18. [CrossRef] [PubMed]

32. Abraham, N.M.; Liu, L.; Lyon, B.; Yadav, A.K.; Narasimhan, S.; Gopalakrishnan, V.; Ansari, J.M.; Jefferson, K.K.; Cava, F.; Jacobs-Wagner, C.; et al. Pathogen-mediated manipulation of arthropod microbiota to promote infection. Proc. Natl. Acad. Sci. USA 2017, 114, E781-E790. [CrossRef] [PubMed]

33. Aivelo, T.; Norberg, A.; Tschirren, B. Bacterial microbiota composition of Ixodes ricinus ticks: The role of environmental variation, tick characteristics and microbial interactions. PeerJ 2019, 2019, e8217. [CrossRef]

34. Newman, M.E.J. The mathematics of networks. New Palgrave Encycl. Econ. 2008, 2, 1-12.

35. Endo, A.; Rothfieldt, L. Studies of a Phospholipid-Requiring Bacterial Enzyme. I. Purification and properties of uridine diphosphate galactose: Lipopolysaccharide alpha-3-galactosyl transferase. Biochemistry 1969, 8, 3500-3507. [CrossRef] [PubMed]

36. Douglas, G.M.; Maffei, V.J.; Zaneveld, J.; Yurgel, N.S.; Brown, J.R.; Taylor, C.M.; Huttenhower, C.; Langille, M.G.I. PICRUSt2: An improved and extensible approach for metagenome inference. BioRxiv 2019, 672295. [CrossRef]

37. Krzywinski, M.; Schein, J.; Birol, I.; Connors, J.; Gascoyne, R.; Horsman, D.; Jones, S.J.; Marra, M.A. Circos: An information aesthetic for comparative genomics. Genome Res. 2009, 19, 1639-1645. [CrossRef]

38. Cabezas-Cruz, A.; Pollet, T.; Estrada-Peña, A.; Allain, E.; Bonnet, S.I.; Moutailler, S. Handling the microbial complexity associated to ticks. In Ticks and Tick-Borne Pathogens; Abubakar, D.M., Ed.; InTechOpen: London, UK, 2018; pp. 1-36.

39. Degli Esposti, M.; Martinez Romero, E. The functional microbiome of arthropods. PLoS ONE 2017, 12, e0176573. [CrossRef]

40. Fierer, N. Embracing the unknown: Disentangling the complexities of the soil microbiome. Nat. Rev. Microbiol. 2017, 15, 579-590. [CrossRef]

41. Faust, K.; Raes, J. Microbial interactions: From networks to models. Nat. Rev. Microbiol. 2012, 10, $538-550$. [CrossRef]

42. Cagua, E.F.; Wootton, K.L.; Stouffer, D.B. Keystoneness, centrality, and the structural controllability of ecological networks. J. Ecol. 2019, 107, 1779-1790. [CrossRef]

43. Van der Heijden, M.G.A.; Hartmann, M. Networking in the Plant Microbiome. PLoS Biol. 2016, 14, e1002378. [CrossRef] [PubMed]

44. Estrada-Peña, A.; Villar, M.; Artigas-Jerónimo, S.; López, V.; Alberdi, P.; Cabezas-Cruz, A.; de la Fuente, J. Use of graph theory to characterize human and arthropod vector cell protein response to infection with Anaplasma phagocytophilum. Front. Cell Infect. Microbiol. 2018, 8, 265. [CrossRef]

45. Poudel, R.; Jumpponen, A.; Schlatter, D.C.; Paulitz, T.C.; McSpadden Gardener, B.B.; Kinkel, L.L.; Garrett, K.A. Microbiome networks: A systems framework for identifying candidate microbial assemblages for disease management. Phytopathology 2016, 106, 1083-1096. [CrossRef]

46. Agler, M.T.; Ruhe, J.; Kroll, S.; Morhenn, C.; Kim, S.T.; Weigel, D.; Kemen, E.M. Microbial hub taxa link host and abiotic factors to plant microbiome variation. PLoS Biol. 2016, 14, e1002352. [CrossRef]

47. Ruhnau, B. Eigenvector-centrality-A node-centrality? Soc. Netw. 2000, 22, 357-365. [CrossRef]

48. Velazquez, E.M.; Nguyen, H.; Heasley, K.T.; Saechao, C.H.; Gil, L.M.; Rogers, A.W.L.; Miller, B.M.; Rolston, M.R.; Lopez, C.A.; Litvak, Y.; et al. Endogenous Enterobacteriaceae underlie variation in susceptibility to Salmonella infection. Nat. Microbiol. 2019, 4, 1057-1064. [CrossRef]

49. Litvak, Y.; Mon, K.K.Z.; Nguyen, H.; Chanthavixay, G.; Liou, M.; Velazquez, E.M.; Kutter, L.; Alcantara, M.A.; Byndloss, M.X.; Tiffany, C.R.; et al. Commensal Enterobacteriaceae Protect against Salmonella Colonization through Oxygen Competition. Cell Host Microbe 2019, 25, 128-139. [CrossRef]

50. Macedo-Raygoza, G.M.; Valdez-Salas, B.; Prado, F.M.; Prieto, K.R.; Yamaguchi, L.F.; Kato, M.J.; Canto-Canché, B.B.; Carrillo-Beltrán, M.; Di Mascio, P.; White, J.F.; et al. Enterobacter cloacae, an Endophyte That Establishes a Nutrient-Transfer Symbiosis with Banana Plants and Protects Against the Black Sigatoka Pathogen. Front. Microbiol. 2019, 10, 804. [CrossRef]

51. Liu, Y.; Zhu, A.; Tan, H.; Cao, L.; Zhang, R. Engineering banana endosphere microbiome to improve Fusarium wilt resistance in banana. Microbiome 2019, 7, 74. [CrossRef] 
52. Narasimhan, S.; Rajeevan, N.; Liu, L.; Zhao, Y.O.; Heisig, J.; Pan, J.; Eppler-Epstein, R.; Deponte, K.; Fish, D.; Fikrig, E. Gut microbiota of the tick vector Ixodes scapularis modulate colonization of the Lyme disease spirochete. Cell Host Microbe 2014, 15, 58-71. [CrossRef]

53. Korach-Rechtman, H.; Freilich, S.; Gerassy-Vainberg, S.; Buhnik-Rosenblau, K.; Danin-Poleg, Y.; Bar, H.; Kashi, Y. Murine Genetic Background Has a Stronger Impact on the Composition of the Gut Microbiota than Maternal Inoculation or Exposure to Unlike Exogenous Microbiota. Appl. Environ. Microbiol. 2019, 85, e00826-19. [CrossRef]

54. Villarino, N.F.; LeCleir, G.R.; Denny, J.E.; Dearth, S.P.; Harding, C.L.; Sloan, S.S.; Gribble, J.L.; Campagna, S.R.; Wilhelm, S.W.; Schmidt, N.W. Composition of the gut microbiota modulates the severity of malaria. Proc. Natl. Acad. Sci. USA 2016, 113, 2235-2240. [CrossRef] [PubMed]

55. Rathinavelu, S.; Broadwater, A.; de Silva, A.M. Does host complement kill Borrelia burgdorferi within ticks? Infect. Immun. 2003, 71, 822-829. [CrossRef]

56. Commins, S.P.; James, H.R.; Kelly, L.A.; Pochan, S.L.; Workman, L.J.; Perzanowski, M.S.; Kocan, K.M.; Fahy, J.V.; Nganga, L.W.; Ronmark, E.; et al. The relevance of tick bites to the production of IgE antibodies to the mammalian oligosaccharide galactose- $\alpha-1,3$-galactose. J. Allergy Clin. Immunol. 2011, 127, 1286-1293. [CrossRef]

57. Hamsten, C.; Starkhammar, M.; Tran, T.A.; Johansson, M.; Bengtsson, U.; Ahlén, G.; Sällberg, M.; Grönlund, H.; van Hage, M. Identification of galactose- $\alpha-1,3$-galactose in the gastrointestinal tract of the tick Ixodes ricinus; possible relationship with red meat allergy. Allergy 2013, 68, 549-552. [CrossRef]

58. Crispell, G.; Commins, S.P.; Archer-Hartman, S.A.; Choudhary, S.; Dharmarajan, G.; Azadi, P.; Karim, S. Discovery of Alpha-Gal-Containing Antigens in North American Tick species believed to induce red meat allergy. Front. Immunol. 2019, 10, 1056. [CrossRef] [PubMed]

59. Chinuki, Y.; Ishiwata, K.; Yamaji, K.; Takahashi, H.; Morita, E. Haemaphysalis longicornis tick bites are a possible cause of red meat allergy in Japan. Allergy 2016, 71, 421-425. [CrossRef] [PubMed]

60. Araujo, R.N.; Franco, P.F.; Rodrigues, H.; Santos, L.C.B.; McKay, C.S.; Sanhueza, C.A.; Brito, C.R.N.; Azevedo, M.A.; Venuto, A.P.; Cowan, P.J.; et al. Amblyomma sculptum tick saliva: $\alpha$-Gal identification, antibody response and possible association with red meat allergy in Brazil. Int. J. Parasitol. 2016, 46, 213-220. [CrossRef]

61. Villar, M.; Pacheco, I.; Merino, O.; Contreras, M.; Mateos-Hernández, L.; Prado, E.; Barros-Picanco, D.K.; Lima-Barbero, F.J.; Artigas-Jerónimo, S.; Alberdi, P.; et al. Tick and host derived compounds modulate the biochemical properties of the cement complex substance. Biomolecules 2020, 10, 555. [CrossRef]

62. Cabezas-Cruz, A.; Valdés, J.; de la Fuente, J. Cancer research meets tick vectors for infectious diseases. Lancet Infect. Dis. 2014, 14, 916-917. [CrossRef]

63. Leinonen, R.; Sugawara, H.; Shumway, M. The sequence read archive. Nucleic Acids Res. 2011, 39, $2010-2012$. [CrossRef] [PubMed]

64. Blankenberg, D.; Gordon, A.; Von Kuster, G.; Coraor, N.; Taylor, J.; Nekrutenko, A.; Galaxy Team. Manipulation of FASTQ data with galaxy. Bioinformatics 2010, 26, 1783-1785. [CrossRef] [PubMed]

65. Bolyen, E.; Dillon, M.; Bokulich, N.; Abnet, C.C.; Al-Ghalith, G.A.; Alexander, H.; Alm, E.J.; Arumugam, M.; Asnicar, F.; Bai, Y.; et al. Reproducible, interactive, scalable, and extensible microbiome data science using QIIME 2. Nat. Biotechnol. 2019, 37, 852-857. [CrossRef] [PubMed]

66. Callahan, B.J.; McMurdie, P.J.; Rosen, M.J.; Han, A.W.; Johnson, A.J.; Holmes, S.P. DADA2: High-resolution sample inference from Illumina amplicon data. Nat. Methods 2016, 13, 581-583. [CrossRef] [PubMed]

67. Katoh, K.; Misawa, K.; Kuma, K.I.; Miyata, T. MAFFT: A novel method for rapid multiple sequence alignment based on fast Fourier transform. Nucleic Acids Res. 2002, 30, 3059-3066. [CrossRef]

68. Price, M.N.; Dehal, P.S.; Arkin, A.P. FastTree 2-Approximately maximum-likelihood trees for large alignments. PLoS ONE 2010, 5, e9490. [CrossRef]

69. Bokulich, N.A.; Kaehler, B.D.; Rideout, J.R.; Dillon, M.; Bolyen, E.; Knight, R.; Huttley, G.A.; Gregory Caporaso, J. Optimizing taxonomic classification of marker-gene amplicon sequences with QIIME 2's q2-feature-classifier plugin. Microbiome 2018, 6, 90. [CrossRef]

70. Yarza, P.; Yilmaz, P.; Pruesse, E.; Glöckner, F.O.; Ludwig, W.; Schleifer, K.H.; Whitman, W.B.; Euzéby, J.; Amann, R.; Rosselló-Móra, R. Uniting the classification of cultured and uncultured bacteria and archaea using $16 \mathrm{~S}$ rRNA gene sequences. Nat. Rev. Microbiol. 2014, 12, 635-645. [CrossRef] 
71. Werner, J.J.; Koren, O.; Hugenholtz, P.; DeSantis, T.Z.; Walters, W.A.; Caporaso, J.G.; Angenent, L.T.; Knight, R.; Ley, R.E. Impact of training sets on classification of high-throughput bacterial 16s rRNA gene surveys. ISME J. 2012, 6, 94-103. [CrossRef]

72. Ren, T.; Wu, M. PhyloCore: A phylogenetic approach to identifying core taxa in microbial communities. Gene 2016, 593, 330-333. [CrossRef] [PubMed]

73. Friedman, J.; Alm, E.J. Inferring Correlation Networks from Genomic Survey Data. PLoS Comput. Biol. 2012, 8, e1002687. [CrossRef] [PubMed]

74. Bastian, M.; Jacomy, M. Gephi: An open source software for exploring and manipulating networks. In Proceedings of the Third International Conference on Weblogs and Social Media (ICWSM 2009), San Jose, CA, USA, 17-20 May 2009; pp. 4-6.

75. Kanehisa, M.; Goto, S. KEGG: Kyoto encyclopedia of genes and genomes. Nucleic Acids Res. 2000, 28, 27-30. [CrossRef] [PubMed]

76. Moura, A.P.V.; Santos, L.C.B.; Brito, C.R.N.; Valencia, E.; Junqueira, C.; Filho, A.A.P.; Sant'Anna, M.R.V.; Gontijo, N.F.; Bartholomeu, D.C.; Fujiwara, R.T.; et al. Virus-like particle display of the $\alpha$-Gal carbohydrate for vaccination against Leishmania Infection. ACS Cent. Sci. 2017, 3, 1026-1031. [CrossRef]

77. Iniguez, E.; Schocker, N.S.; Subramaniam, K.; Portillo, S.; Montoya, A.L.; Al-Salem, W.S.; Torres, C.L.; Rodriguez, F.; Moreira, O.C.; Acosta-Serrano, A.; et al. An $\alpha$-Gal-containing neoglycoprotein-based vaccine partially protects against murine cutaneous leishmaniasis caused by Leishmania major. PLoS Negl. Trop. Dis. 2017, 11, e0006039. [CrossRef]

78. Mateos-Hernández, L.; Rakotobe, S.; Defaye, B.; Cabezas-Crus, A.; Simo, L. A Capsule-based model for immature hard tick stages infestation on laboratory mice. J. Vis. Exp. 2020, 161. [CrossRef]

79. Castillo, M.; Martín-Orúe, S.M.; Manzanilla, E.G.; Badiola, I.; Martín, M.; Gasa, J. Quantification of total bacteria, enterobacteria and lactobacilli populations in pig digesta by real-time PCR. Vet. Microbiol. 2006, 114, 165-170. [CrossRef]

80. Pfaffl, M.W. A new mathematical model for relative quantification in real-time RT-PCR. Nucleic Acids Res. 2001, 9, e45. [CrossRef]

Publisher's Note: MDPI stays neutral with regard to jurisdictional claims in published maps and institutional affiliations.

(C) 2020 by the authors. Licensee MDPI, Basel, Switzerland. This article is an open access article distributed under the terms and conditions of the Creative Commons Attribution (CC BY) license (http://creativecommons.org/licenses/by/4.0/). 